\title{
A trama conflituosa das políticas públicas: Lógicas e projetos em disputa
}

FRANCISCO FONSECA

Fundação Getulio Vargas / Escola de Administração de Empresas de São Paulo, Departamento de Gestão PúblicA,

SÃO PAULO - SP, BRASIL

Pontifícia Universidade Católica de São Paulo / Departamento de Política, SÃo Paulo - SP, Brasil

\section{Resumo}

O artigo tem por objetivo analisar o conjunto dos estudos que compõem o número temático especial do periódico Cadernos EBAPE.BR, intitulado "Políticas Públicas em Múltiplas Dimensões". Muito além de mera apresentação formal, procurou-se analisar a constituição da "trama conflituosa" das políticas públicas como fio condutor dos trabalhos. Observou-se que os conflitos, as contendas e os vetos são a lógica das políticas e devem constituir fonte de pesquisa para futuros trabalhos, uma vez que são negligenciados por visões normativas, formalistas ou metafísicas.

Palavras-Chave: Políticas Públicas. Conflitos. Disputas. Vetos. Projetos Políticos.

\section{The conflicting drama of public policy: logic and projects in dispute}

\section{Abstract}

The purpose of this article is to analyze the group of studies that make up the special edition of the Cadernos EBAPE.BR journal, which is entitled "Public Policies in their Multiple Dimensions". Beyond offering a mere formal presentation, the article seeks to analyze how this "conflicting drama" of public policies is constituted as a common thread of these studies. It notes that conflicts, strife and vetoes are all part of the logic of such policies and should constitute a source of research for future work, especially as they tend to be neglected by normative, formalistic or metaphysical points of view.

Keywords: Public Policies. Conflicts; Disputes. Vetoes. Political Projects.

\section{La trama conflictiva de las políticas públicas: lógicas y proyectos en disputa}

\section{Resumen}

Se objetiva analizar el conjunto de los estudios que componen el número temático especial de este Cadernos EBAPE.BR, titulado “Políticas Públicas en Múltiples Dimensiones". Más allá de una mera presentación formal, se trató de analizar la constitución de la "trama conflictiva" de las políticas públicas como hilo conductor de los trabajos. Se observó que los conflictos, las luchas y los vetos son la lógica de las políticas y deben constituir una fuente de investigación para futuros trabajos, una vez que son descuidados por visiones normativas, formalistas o metafísicas.

Palabras Clave: Políticas Públicas. Conflictos. Disputas. Vetos. Proyectos Políticos. 


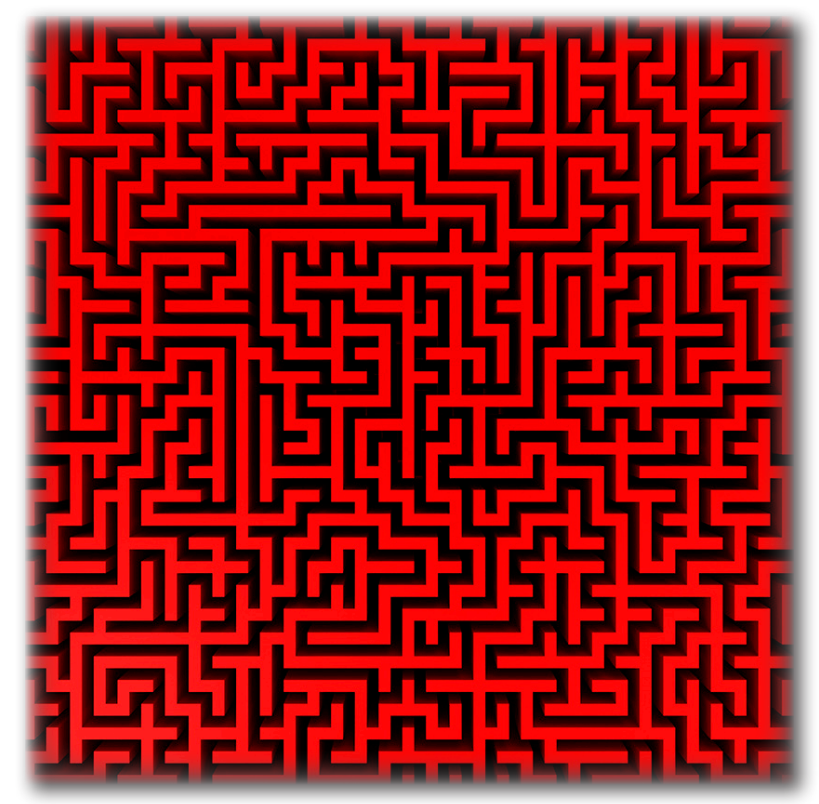

\section{INTRODUÇÃo}

O termo "políticas públicas" tem sintetizado, nas últimas décadas, grande leque de conceitos acadêmicos, de formulações de "comunidades epistêmicas", de ações governamentais, de embates na chamada esfera pública e de inúmeras disputas de variadas ordens.

O dissenso é a característica central, espécie de pressuposto que orienta a tentativa de definição conceitual e o modus operandi expresso em projetos específicos de políticas públicas. Em outras palavras, o dissenso exemplifica fundamentalmente o conflito: de paradigmas; de modelagem dos programas; de visões e percepções de mundo; de interesses dos mais diversos grupos, entre os quais as grandes corporações; de classes sociais e suas frações; entre outros.

Esse conjunto de questões é agudizado nas sociedades capitalistas, para além da maior ou menor extensão da desigualdade, uma vez que a produção e a apropriação da renda e das oportunidades se dá - por complexos mecanismos - de forma assimétrica por grupos sociais específicos. Embora a experiência da Escandinávia difira relativamente desse roteiro, trata-se de situação atípica que apenas confirma uma das regras estruturais do capitalismo: a desigualdade.

Contudo, tais assertivas, que estruturam o mundo real das políticas públicas: não são devidamente abordadas por grande parte das teorias que as retratam e pelo chamado mainstream: nas esferas acadêmica e governamental e no debate público. Perspectivas normativas, formalistas ou teórico/metafísicas parecem dominar o cenário da análise das políticas públicas, com exceções.

Afinal, visões acerca do "bem comum", das "causas públicas", dos "interesses confluentes", da "igualdade sem opositores", da "conciliação entre grupos e classes", dos "consensos", entre outros - mesmo que por vezes não se apresentem de forma ostensiva -, parecem subsumir o manancial de conflitos e disputas havido antes, durante e depois de formulada certa política pública. Mais ainda, o abandono de conceitos como "modelo de acumulação" e seus impactos na economia (novas formas de produção e de circulação de bens e serviços), na sociedade (reconfiguração de classes sociais, cuja conceituação tem sido simplesmente deixada de lado), no Estado (capacidade de compreender e responder às novas demandas) assim como nas políticas públicas (clareza quanto aos seus objetivos em razão dos impactos estruturais advindos do modelo de acumulação);

* Fonte da imagem: Shutterstock - ID 45760429. Disponível em www.shutterstock.com. Acesso em 29 jun. 2016. 
assim como as novas complexidades e nuances da "luta de classes" e seus impactos nas políticas públicas são apenas alguns exemplos da trama das políticas públicas que, embora fortemente ocultadas, trazem em primeiro plano a necessidade de ocupação desse vácuo analítico.

Este texto objetiva refletir criticamente sobre essa trama, cuja marca - reitere-se - é o dissenso, o conflito e os pontos de veto, dando sequência às reflexões de minha autoria (FONSECA, 2013). Nas reflexões que seguem, analisa-se, por meio de projetos específicos em disputa que constam nesta edição especial do Cadernos EBAPE.BR, as tramas conflituosas das políticas públicas. Nesse sentido, apresento criticamente os textos em que são analisadas as "Políticas Públicas em Múltiplas Dimensões".

Entretanto, antes de analisar os projetos específicos em disputa, deve-se compreender que a dinâmica das políticas públicas na perspectiva dos conflitos, das contendas e dos vetos se dá em sistemas políticos e regimes de governo concretos. Isso implica considerar o papel dos arranjos institucionais em sua relação com o modus operandi das políticas públicas. No caso brasileiro, na República Federativa cujo presidencialismo é marcado pelo multipartidarismo e, consequentemente, pela coalizão de partidos, a lógica dos conflitos adquire contornos partidários, regionais e setoriais. De acordo com João Mendes Rocha e Djalma Freire Borges, no artigo “Políticas públicas coordenadas e presidencialismo de coalizão: o caso do Promeso":

Apesar de chegarem conjuntamente ao poder, alguns desses partidos [que compõem coalizões governamentais - FF] possuem orientações ideológicas muito heterogêneas, bem como lógicas particulares de operação marcadas pelas suas relações e compromissos com os grupos de interesse e com porções do território nacional, que ocupam espaços diferentes nas suas agendas, constituindo-se em verdadeiras redes.

Trata-se de um aspecto importante [...] que se fragmenta por projetos partidários, regionais e setoriais. [...]

Esse quadro sinaliza para uma compreensão mais profunda das políticas públicas, evitando-se o lugarcomum das análises que têm se centrado somente nas questões objetivas orientadoras de tais instrumentos de ação governamental. De fato, essa perspectiva traz ao debate algo além das objetividades, resgatando aspectos subjetivos que influenciam todo o curso da política pública, tais como: culturas organizacionais, conflitos e disputas entre grupos de interesse e partidos políticos (ROCHA e BORGES, 2016, p. 441-442).

Como se observa, no regime de coalizão do presidencialismo brasileiro ${ }^{1}$, a coalizão do poder com vistas à obtenção de maioria no Congresso Nacional implica partilhar cargos, orçamento e conteúdo das políticas públicas: estas tendem a ser, em larga medida, contraditórias se observadas entre os diversos ministérios. Portanto, grupos de interesse e bases sociais que sustentam - em diversos sentidos - os partidos políticos levam à arena institucional do Estado as disputas de classes sociais e suas frações e outros interesses corporativos, em sentido amplo. Isso ocorreu e ocorre em todos os governos de coalizão após a redemocratização, assim como, em decorrência, com praticamente todos os partidos que “jogam o jogo" parlamentar/institucional².

Ainda segundo os autores:

É inegável que as políticas públicas, dependendo do que tratem, podem ser objeto de maior consenso e, assim, se revelarem menos conflituosas. Evidente que nem sempre é possível esta pacificação de interesses, mas ao se decidir pelo desenho de uma política pública, busca-se ao menos, em tese, uma superação das divergências, o que tem sido bastante dificultado em função dos pontos elencados anteriormente (ROCHA e BORGES, 2016, p. 442).

Portanto, embora os conflitos sejam perenemente negociados - com maior ou menor sucesso -, o consenso é exceção e não regra, o que reforça a tese de que as políticas públicas são essencialmente conflitivas, isto é, sua dinâmica tem como

\footnotetext{
${ }^{1}$ Em junho de 2016 o Brasil possuía 35 partidos legais, sendo que outros 30 postulam ser legalizados.

${ }^{2}$ Nesse sentido, tentativas midiáticas e de outros setores para especificar tal prática como pertencente a um partido, grupo político ou governo são inteiramente descabidas, como demonstram os dados desde o Governo Sarney.
} 
pressupostos as contendas e os vetos, paralelamente à consecução de demandas efetivadas assimetricamente, por meios diversos, por grupos sociais específicos e organizados. Note-se que conflitos podem ter muitas características: hard e/ou soft.

Dessa forma, não há políticas públicas sem atores concretos, uma vez que sem eles a ação política como um todo e particularmente as políticas públicas - que são derivadas daquelas - seriam meras abstrações. Além do mais, no campo da Administração Pública, que é justamente o aparato material e operacional do Estado moderno, os elementos fundantes são a mundaneidade, a oficialidade, a burocracia e a busca pelos fins materiais. Mesmo dimensões imateriais, como cultura e bem-estar social, só se viabilizam por meio de ações concretas, que envolvem legislação, orçamento, recursos humanos, logística etc.: tudo isso nos leva a observar o papel dos atores.

É a partir dessa perspectiva que o estudo de Ana Cláudia N. Capella - intitulado "Um estudo sobre o conceito de empreendedor de políticas públicas: Ideias, Interesses e Mudanças" - pode ser compreendido. Embora voltado à discussão teórica do conceito de "empreendedor de políticas públicas", tal conceito almeja abarcar realidades distintas ao mobilizar categorias analíticas que privilegiam aspectos diversos. Segundo Baumgartner e Jones - uma das principais referências neste assunto:

Every interest, every group, every policy entrepreneur has a primary interest in establishing a monopoly - a monopoly on political understandings concerning the policy of interest, and an institutional arrangement that reinforces that understanding. Nobody likes protracted conflict and continual competition. Much preferable to a system of conflict is one where each side retreats into a given area where its influence is uncontested. ${ }^{3}$ (BAUMGARTNER e JONES, 1993, p. 6, Apud CAPELLA, 2016, p. 492.)

Como se observa nessa passagem, os atores agem tendo como lógica o conflito, embora sua extensão e profundidade representem instabilidade no sistema político e nos subsistemas que produzem políticas públicas. Ainda assim, o tensionamento maior ou menor depende da posição em que cada grupo - atores políticos - está localizado em termos de poder, legitimidade, influência etc. ${ }^{4}$ Igualmente, o estabelecimento do "monopólio da verdade" acerca do diagnóstico e das proposições para determinados problemas que as políticas públicas se propõem a resolver implica disputa conceitual, em que as "comunidades epistêmicas" conflitam - em arenas distintas e com recursos assimétricos - com vistas a deter certas verdades, portanto consideradas "válidas" em detrimento de outras.

Em decorrência, ao analisar o modelo de "coalizões de defesa", intitulado advocacy coalition framework (criado por Sabatier e Jenkins-Smith), Ana Cláudia N. Capella afirma, que:

De acordo com o modelo, no interior de cada subsistema podemos encontrar coalizões [...] que compartilham crenças e que, em determinados momentos, adotam estratégias diferentes para realizar seus objetivos de mudança. A escolha de estratégias conflitantes entre coalizões de um mesmo subsistema gera uma situação de competição em que a atuação de mediadores torna-se fundamental para reduzir o conflito. Esses mediadores, chamados de policy brokers, são agentes políticos que atuam como intermediários no conflito entre as coalizões ${ }^{5}$ (CAPELLA, 2016, p. 494).

Logo, as coalizões de defesa agenciam ideias, que expressam interesses, envolvendo-se em competições e disputas e interpondo vetos em âmbitos distintos: político, institucional, social, acadêmico, cujos reflexos - pode-se dizer - expandem-se, por vezes, aos meios de comunicação e ao senso comum. Não é possível saber o limite entre "ideias desinteressadas" e "coalizões de interesse": afinal, ideias e interesses se imiscuem e as coalizões são a expressão desse conflito amplo e complexo.

\footnotetext{
3 "Todo o interesse, todo o grupo, todo o empreendedor de política tem um interesse primordial em estabelecer um monopólio - um monopólio sobre entendimentos políticos no âmbito da política de interesse, e um arranjo institucional que reforça esse entendimento. Ninguém gosta de conflito prolongado e de competição contínua. Mais preferível a um sistema de conflito é aquele em que cada lado retira-se para uma determinada área, onde sua influência é incontestável". (Tradução do autor).

${ }^{4}$ É interessante observar como áreas distintas das Ciências Sociais tratam o tema da posição (social, societária ou institucional) de cada ator em determinado contexto. Particularmente, Pierre Bourdieu argumenta que a posição em determinado "campo" determina fortemente a visão de mundo e os interesses dos atores: caso, por exemplo, da defesa da "ciência normal" ou da "contestação a ela". Já Carlos Matus (1991), embora por meio de perspectiva bastante distinta dessa, entende que o "jogo da política" - em sentido lato, que envolve ações governamentais, planejamento e políticas públicas - implica olhar o mundo de acordo com a "posição situacional" de cada ator. Daí a perspectiva do Planejamento Estratégico Situacional (PES) que, baseada na ação tecno-política, implica um modo de governar e de fazer política tendo como referência, reitere-se, as "posições situacionais" dos atores.

${ }^{5}$ Capella (2016, p. 10)
} 
Daí o papel dos mediadores (pessoas e/ou instituições) dos conflitos entre as coalizões. Embora essa perspectiva, reitere-se, seja conceitual, pode ser aplicada em situações concretas por meio de políticas públicas específicas.

Vejamos, agora, como projetos específicos de políticas públicas expressam efetivamente contendas, com resultados distintos, do complexo processo de agendamento, formulação e implementação - entre outros processos macro, meso e micro de políticas públicas.

\section{PROJETOS EM DISPUTA}

Embora de forma panorâmica, nesta seção - como dissemos - são analisadas diversas políticas públicas que demonstram, direta e indiretamente, a lógica conflituosa e as disputas quanto à formulação de políticas.

Nesse sentido, enfatize-se que políticas públicas somente se concretizam por meio de projetos específicos - empíricos, portanto -, uma vez que, segundo Francisco Ebeling, no estudo "Variedades de capitalismo e complementaridades institucionais: uma análise da política petrolífera brasileira e da viabilidade do 'Projeto Pré-Sal'”:

Diferentemente dos autores que veem as instituições em equilíbrio, neste artigo considera-se que os conflitos, as tensões e as contradições que ocorrem quando as políticas públicas [...] [relacionadas ao Pré-Sal - FF] são reavaliadas e redimensionadas - em muitos casos sem sucesso -, demandam leituras críticas do conceito [de "complementaridades institucionais" - FF]. [...](EBELING, 2016, p. 420).

Como se observa, no complexo campo do petróleo, as políticas públicas que o viabilizam convivem lado a lado com as que delas derivam, caso do uso dos recursos advindos do Pré-Sal. Todo esse complexo jogo é marcado por inúmeros conflitos, uma vez que não apenas há diversos atores em cada política específica como uma miríade de questões em disputa. Francisco Ebeling reitera essa perspectiva ao afirmar que "as negociações comerciais internacionais envolvendo o petróleo estão longe de serem um jogo de 'ganha-ganha' que tende ao equilíbrio" (EBELING, 2016, p. 434 e 435). Mais ainda, afirma que "para o estudo das políticas públicas, é muito importante perceber que as instituições, em muitos casos, administram o conflito e o dissenso, e não situações de calmaria (EBELING, 2016, p. 436). Portanto, as premissas que informam a lógica e o modus operandi das políticas públicas são os atores em posições assimétricas e, por vezes, com percepções distintas acerca de todo o processo - com todas as suas particularidades e temporalidades - de formulação e implementação das políticas públicas.

Em outras palavras, a perda ou percepção de perda (quanto à validade, correção e efeitos de uma dada política pública) em dado momento do processo implica tentativa de veto e/ou obstrução nos momentos posteriores, além da permanente busca - isto é, em todos os momentos - por aliados com vistas à formação de "coalizões de defesa", como analisei em Fonseca $(2013$, p. 404)

[...] no chamado "ciclo das políticas públicas" - agenda, formulação, implementação e avaliação -, cada etapa permite intervenções distintas dos grupos que se sentem, real ou imaginariamente, atingidos. Isso implica a adoção de "vetos", que se dão de formas distintas dependendo da correlação de forças e dos recursos de poder dos atores em disputa.

Em outras palavras, no mundo real da política, "políticas públicas" expressa uma infindável teia de interesses, que congrega desde a capacidade técnica de elaborar e implementar um dado programa, as contendas orçamentárias, e as combinações e recombinações de interesses em cada etapa do ciclo.

Como políticas em geral e políticas públicas em particular exigem regulação e regulamentação do Estado, de certa forma esse dueto (regulação/regulamentação) expressa uma forma específica, embora macro, de políticas públicas: as assim chamadas "regulatórias". Nesse sentido, no artigo "Antagonismo, modernismo e inércia: a política regulatória brasileira em três atos", Bruno Queiroz Cunha aponta a existência do que denomina "três atos" (ou momentos) na recente formulação de

${ }^{6}$ Deve-se ressaltar que consideramos o chamado "ciclo das políticas públicas" mera organização pedagógica do que propriamente existente no mundo real, em especial quanto ao seu caráter etapista. 
uma política específica de regulação, isto é, entre os anos 1990 e 2000. Tais atos seriam a expressão do jogo entre os diversos atores, tais como "empresas privadas", nos diversos setores regulados e de tamanhos, capacidades e poder distintos; o "Estado", por meio de regulamentação e de suas agências regulatórias; e os "consumidores". O primeiro ato teria se voltado ao questionamento das "premissas e resultados da reforma regulatória dos anos 1990", e o segundo ato seria o "retorno às 'boas práticas'”. Para o autor:

O fato do avanço da agenda de qualidade regulatória ter sido obstruído pode ser visto como um dos motivos do terceiro ato [o que o autor chamou de "o contramovimento consumerista" - FF]. Ele reflete diretamente a deterioração da relação entre empresas reguladas e usuários dos serviços. O Estado, por seu turno, não foi capaz de vencer a inércia e mediar antecipadamente o conflito entre essas partes, o que contribuiu para a formação de um ambiente de relativa crise. Este terceiro ato, assim, repercute a crescente insatisfação por parte de usuários de serviços regulados, os quais registraram em grandes números as queixas a respeito da baixa qualidade dos serviços regulados (CUNHA, 2016, p. 481).

Como se observa, a política regulatória - que, reitere-se, regula conflitos de outras políticas públicas, sendo ela própria uma política pública - teria assumido feições distintas, os chamados "atos", ou "momentos", em razão da combinação e recombinação crítica, isto é, conflituosa entre os três grandes atores envolvidos: agentes privados, Estado e consumidores. Cada um deles com suas particularidades, objetivos, interesses e percepções em cada situação específica. A complexa lógica do conflito, com suas inúmeras formas de expressão e de negociação expressou-se vigorosamente no período estudado pelo autor, tal como constata o estudo em tela.

Outra política pública específica refere-se ao Sistema Nacional de Inovação, com foco no setor de energia, e o artigo de Aline Dario Silveira et al. - intitulado "Análise do Sistema Nacional de Inovação no setor de energia na perspectiva das políticas públicas brasileiras" - demonstra como tal sistema, ao constituir política pública, articula diversos atores e grupos de interesse, cujas ações são fortemente contenciosas.

Afinal, a definição de quais setores serão beneficiados, com recursos, apoio à inovação tecnológica, transferência de tecnologia, legislação e outros mecanismos tecnoburocráticos de incentivo é objeto de intensa disputa. Logo, os contornos técnicos, jurídicos, orçamentários e operacionais da política pública de inovação é alvo de interesses e percepções, viabilizados politicamente. No setor elétrico, em particular, cujo papel é matricial, uma vez que todos os setores empresariais e sociais dependem de energia, a atuação de atores-chave - Estado em diversos âmbitos, agência de regulação, "produtores" de energia, consumidores empresariais e residenciais, entre outros - implica assimetrias e interesses distintos. Segundo Silveira, Carvalho, Rodrigues et al. (2016, p. 523):

[...] sugere-se que o direcionamento dos esforços do país deve estar mais bem posicionado na execução efetiva das ações de promoção inseridas nas políticas e seus instrumentos, diminuindo a distância entre a geração de conhecimento e tecnologia e o seu uso efetivo pela sociedade. Logo [...], salientam-se as fragilidades da própria política aqui analisada, seu planejamento, o papel dos atores, desenhos e formulações, assim como as avaliações dessas políticas e ações envolvendo os atores e grupos de interesse da sociedade.

Dessa forma, nota-se como a "inovação", que aparenta ser um tema consensual, tal como outros temas, na verdade oculta posições e concepções acerca do que deveria ser - para atores específicos envolvidos - uma política nacional. Exemplos internacionais, paradigmas, volume de recursos, papel do Estado, seu aparato institucional e a relação deste com setores privados os mais diversos (centros de pesquisa, empresas privadas, laboratórios diversos, organismos ambientalistas nacionais e internacionais), entre outros, animam as disputas pela política pública de inovação na área de energia em perspectiva fortemente contenciosa.

No que tange à relação entre empresas privadas e governos, especificamente o apoio destes perante a "internacionalização das atividades empresariais", o artigo "A internacionalização de empresas na agenda governamental contemporânea de desenvolvimento: reflexões críticas e analíticas para os negócios internacionais", de Diego Bonaldo Coelho e Moacir de Miranda Oliveira Jr., aponta a complexidade conflituosa dessa "parceria". Afinal, trata-se do apoio de governos - por meio de financiamentos, empréstimos, cooperação técnica, atuação diplomática, comércio exterior, acordos internacionais etc. 
- a empresas e setores empresariais cuja implicação é a priorização de determinados setores, via de regra em detrimento de outros. De acordo com os autores, a relação governo/setores empresariais com vistas à formulação de políticas públicas de internacionalização empresarial:

[...] inclui agendas e barganhas entre grupos governamentais e empresariais que determinarão suas diretrizes e instrumentos. Afinal, tais processos revelam, pela ótica das ações não mercadológicas empresariais, como lobbying, advocacy, financiamento de campanhas e outras, um contexto de formulação e de decisão de agenda de políticas que não é linear e tampouco horizontalizado na maior parte dos casos. Pelo contrário, pressupõe diversos níveis de complexidade, interações e barganha, resultantes de diversos interesses e conflitos setoriais. Não por acaso, considerado o Brasil, ainda não há, por parte do Governo Federal, um marco institucional mais explícito e deliberado das políticas governamentais de apoio à internacionalização em curso no País. [...] uma vez que o tema da internacionalização de empresas, particularmente via investimentos diretos, ainda não é consenso em todos os setores da sociedade como um problema público objeto de políticas governamentais [...] (COELHO e OLIVEIRA JR., 2016, p. 546).

Note-se que a inexistência de "consenso" implica a interposição de vetos de segmentos empresariais quanto ao apoio à internacionalização, seja por ter foco no mercado interno, seja por não fazer parte dos setores elegidos como internacionalizáveis, seja simplesmente por não ter interesse nessa prática, por motivos distintos, incluindo-se a composição do capital.

Por outro lado, a prática do lobbying e financiamento de campanhas políticas revela, por si só, estratégia que tende a privilegiar grupos mais poderosos, em termos de recursos econômicos e políticos, opondo-se claramente a grupos menores ou menos poderosos quanto a esses recursos. A lógica conflituosa dá-se, portanto, em dupla direção: na existência mesma de uma política voltada à internacionalização de empresas e no privilegiamento de determinados setores em detrimento de outros.

Ainda nessa perspectiva das relações entre Estado e setores específicos, a lógica do conflito permanece, mas adquire diversos formatos. No caso a seguir, referente a segmentos pobres do Semiárido, tal lógica se estabelece na relação entre comunidade organizada (organização societária) e os poderes públicos municipal e federal.

Trata-se do programa conhecido como "cisterna para todos", implementado no Semiárido brasileiro. Por meio do artigo intitulado "Uma discussão sobre a possibilidade da criação institucional e sinergia entre Estado e sociedade: o caso do P1MC no Semiárido brasileiro", de Jackeline Amantino de Andrade e José Raimundo Cordeiro Neto, os conflitos entre sociedade organizada e os poderes Legislativo e Executivo, notadamente municipais, da região do Semiárido (Vale do Rio São Francisco, em especial localizados na microrregião de Juazeiro/BA), são trazidos à tona, mas também, embora em menor nível, referentes às instituições federais interagentes na região do programa. Para os autores:

[...] as ações que levaram à criação da ASA Brasil [Articulação do Semiárido Brasileiro] e à constituição do P1MC [Programa Um Milhão de Cisternas Rurais] originaram-se exclusivamente da iniciativa de organizações da sociedade civil. Lembrando que, em âmbito local e regional, as relações dessas organizações com as organizações estatais foram sempre permeadas por conflitos e contradições.

[...] Por exemplo, no início dos anos 1990, a Codevasf [Companhia de Desenvolvimento do Vale do São Francisco e do Parnaíba] disponibilizou assistência técnica [...] para assessorar a elaboração de planos de abastecimento hídrico propostos pelas organizações da sociedade civil a fim de se constituírem em projetos de lei nas Câmaras de Vereadores dos municípios da microrregião de Juazeiro. [...] Esses projetos, no entanto, não foram considerados pelos legislativos municipais, evidenciando-se as distâncias, contradições e os conflitos [...] [entre sociedade e Estado, notadamente no plano municipal - FF] (ANDRADE e CORDEIRO NETO, 2016, p. 561-562).

Paralelamente ao apontamento das assimetrias políticas e sociais, dos conflitos e das dificuldades de coordenação federativa em perspectiva histórica, o artigo demonstra como a construção do exitoso e grandiloquente programa de construção de cisternas se deu essencialmente pelo processo bottom-up. Para os autores do estudo, os poderes públicos locais foram percebidos pelos cidadãos como ilegítimos, pois vinculados a práticas de cooptação e clientelismo. No caso relatado na passagem acima, a própria desarticulação entre instituições federais ou com vínculos federais (caso da Codevasf) com as instituições locais denota conflitos 
e contradições federativas e de coordenação - sem contar os aspectos mais propriamente vinculados à trajetória histórica, isto é, o path dependence no âmbito local -, inviabilizando a "sinergia entre Estado e sociedade". O sucesso do programa teria se dado, segundo os autores, muito mais pelo protagonismo de amplos grupos provenientes da sociedade politicamente organizada em parceria - não sem outras formas de conflito - com instituições federais. A lógica do conflito desloca-se, portanto, ao âmbito da (des)coordenação federativa; em menor medida, portanto, entre atores privados em sua relação com o Estado.

Outra política pública analisada neste número especial do Cadernos EBAPE.BR refere-se ao "Programa de assistência técnica para o desenvolvimento de pequenas propriedades leiteiras em Valença-RJ e região Sul Fluminense", escrito por Marcio Silva Borges, Cezar Augusto M. Guedes e Maria Cristina D. Castro. Trata-se da análise da vinda de empresas multinacionais no setor lácteo no município de Valença, no Rio de Janeiro, então dominado por pequenos agricultores. Para os autores, desde a década de 1990, com a abertura da economia brasileira:

[...] o processo de modernização foi intensificado no setor lácteo brasileiro. A maior parte dos laticínios brasileiros, seja de capital estrangeiro ou nacional, exige o processo de granelização, que acarretou as seguintes tendências: evolução da produção média e redução do número de fornecedores da maior parte desses laticínios. As empresas multinacionais, em curto espaço de tempo, reduziram seus fornecedores em cerca de $20 \%$ ao ano e elevaram a produção média em $45 \%$ ao ano.

Efetivamente, esse processo ocorreu no país por pressões que as empresas multinacionais exercem sobre os produtores de leite in natura, no sentido de aquisição de tanques de expansão e melhoria da produtividade de rebanho [...]

O pequeno produtor que não tem condições de se adaptar às exigências dos laticínios e processadoras [...] está migrando de forma abrupta para a chamada "informalidade", mais um motivo para a consolidação dessa dicotomia entre os produtores (BORGES, GUEDES e CASTRO, 2016, p. 578).

Nesse caso, a presença de novos atores internacionais, caso das empresas multinacionais de laticínios, alterou vigorosamente o mercado regional e local - com impactos nacionais - de produção de leite, implicando a necessidade de políticas públicas de outra natureza, isto é, voltadas aos pequenos produtores, cuja produção é voltada ao mercado interno ou mesmo ao autoconsumo, na perspectiva de tirá-los da ou impedir que fossem para a informalidade.

Nesse sentido, o estudo analisa o "Programa Balde Cheio", que almejava possibilitar: que as unidades produtivas familiares tivessem acesso à tecnologia adaptada às suas necessidades; que a assistência técnica fosse disponibilizada a custos baixos; que houvesse a transmissão de "técnicas de gestão rural" e de "boas práticas sanitárias" que, por seu turno, deveriam estar em conformidade com a produção e comercialização de produtos agropecuários. Esse programa - uma política pública federal - foi instituído com vistas justamente a remediar a nova situação criada pela entrada dos grandes laticínios internacionais.

Portanto, essa experiência demonstra como a entrada de determinados atores, notadamente as empresas multinacionais, em geral de grande porte, pode alterar sobremaneira, reitere-se, ambientes locais e regionais, com impactos nacionais. 0 conflito entre setores tão díspares do capital (os transnacionais e os pequenos produtores) pendeu fortemente para o grande capital. Ao Estado (brasileiro), incapaz de impedir que a "regra do mais forte" prevalecesse, restou mitigar os efeitos do poder do grande capital por meio de uma política pública importante, porém eminentemente compensatória?.

Retomando o tema dos "atores" nas políticas públicas, mas de forma aplicada, o texto de Alex S. Macedo, Valderí C. Alcântara, Luís F. S. Andrade et al., intitulado "O papel dos atores na formulação e implementação de políticas públicas: dinâmicas,

\footnotetext{
${ }^{7}$ De acordo com Claus Offe (1984, p. 124-125, grifo do autor), há quatro “determinações funcionais" ao Estado capitalista que tornariam o poder do Estado perante o capital dependente e relativo: “a) A privatização da produção: o poder público está estruturalmente impedido de organizar a produção material segundo seus próprios critérios "políticos". [...] b) Dependência dos impostos: o poder público depende, indiretamente, através de mecanismos do sistema tributário, do volume da acumulação privada. [...] c) A acumulação como ponto de referência: como o poder estatal depende do processo de acumulação capitalista, sem ser ele mesmo capaz de organizar este processo, o interesse supremo e mais geral dos detentores do poder do Estado consiste em manter as condições de exteriorização de seu poder através da constituição de condições políticas que favoreçam o processo privado de acumulação. [...] d) $A$ legitimação democrática: [...] O exercício do poder através dos mecanismos democrático-representativos da formação das vontades e da regulamentação dos conflitos tem o sentido, no contexto do Estado constitucional burguês, de assegurar de forma politicamente duradoura - e não somente através de preceitos constitucionais - a delimitação da esfera privada e da esfera de liberdade econômica, de forma a defender essa esfera de liberdade de possíveis intrusões por parte do Estado".
} 
conflitos e interesses no Programa Mais Médicos" (PMM), (2016, p. 612), afirma que houve intensas críticas de setores corporativos dos médicos, de grupos conservadores e de organizações da mídia ao PMM:

Observou-se que os diversos atores [...] participaram do processo motivados por interesses, ideologias e objetivos diversificados. Dessa forma, os conflitos permearam todo o processo, desde a proposta do programa, o anúncio, a aprovação da Lei, a chegada dos diversos médicos, até o início de suas atividades nos hospitais por todo o país. No início de 2014 , novas etapas do programa foram lançadas e ainda existiam opiniões divergentes por parte dos atores.

É interessante observar a menção aos conflitos em todo o processo - da elaboração da proposta à vinda dos médicos estrangeiros - de constituição/aplicação dessa política pública de saúde. Mais ainda, o papel da mídia é ressaltado no texto, no sentido de ter-se portado como ator político/ideológico, por sua vez vocalizando ideias, preconceitos, imagens e interesses de setores de classe média e das corporações de médicos; temerários, estes, em perder benefícios e prestígio. Afinal:

Empiricamente observou-se que a mídia de massa posicionou-se com discursos contra o Programa Mais Médicos [...]: relacionou o atraso de Cuba com a qualidade dos médicos, apontou a questão de não passar pelo Revalida e de interesses não públicos do Governo com Cuba, trouxe o tema do comunismo etc. Tudo isso proporcionou também nas mídias sociais uma luta discursiva [...] (MACEDO, ALCÂNTARA, ANDRADE et al., 2016, p. 609).

O papel da mídia como "aparelho privado de hegemonia" que atua no sentido de intermediar interesses no âmbito da chamada "esfera pública" - como tenho apontado em inúmeros textos (FONSECA, 2005; 2010) -, é confirmado pelo artigo em tela, pois atuou vigorosamente de forma contrária ao Programa Mais Médicos, divulgando negativamente imagens e percepções com vistas à vulgarização dessa política pública cujo objetivo é levar médicos aos rincões do país. Serviu, nesse sentido, a dois propósitos: criticar o Governo Dilma Rousseff, a quem fazia oposição ${ }^{8}$, e canalizar os interesses das classes médias e das corporações dos médicos. Atuou, portanto, diretamente no conflito: de ideias, de interesses e de percepções.

A "percepção" a respeito de políticas públicas é, dessa forma, muito significativa, pois, afinal, os conflitos são revestidos de disputas simbólicas que, dessa forma, justificam posições. Nesse sentido, o texto “A conferência nacional das cidades como instrumento de políticas públicas para o desenvolvimento territorial: a percepção dos conselheiros nos processos participativos e deliberativos", de Lamounier E. Villela, Marcelo O. Vidal, Antonione C. Araújo et al., explora os instrumentos de participação como forma de gestão das políticas públicas incidindo diretamente nos conflitos sociais. Para os autores:

Alguns instrumentos de governo para a participação social no Brasil são recentes e ainda pouco estudados. Sem esses instrumentos, a gestão social torna-se improvável e a tendência do poder público servir exclusivamente aos interesses do capital se amplia. Não é por acaso que muitas questões sociais e urbanas foram deixadas de lado no planejamento de nossas cidades, o que ocasionou deficiências graves no desenvolvimento do território (VILLELA, VIDAL, ARAÚJO et al., 2016, p. 621).

A clareza quanto ao papel da participação social no tocante ao conflito de classes, em que a referência quanto ao poder do capital, notadamente no universo urbano, implica ocupação do espaço, valorização imobiliária e expulsão dos pobres para as periferias ainda mais longínquas em ambiente marcadamente desigual.

Nesse sentido, os autores afirmam que "o papel do Estado passa a ser a coordenação de interesses divergentes em busca de critérios de redistribuição, a exemplo do que se almeja com as conferências das cidades” (VILLELA, VIDAL, ARAúJO et al., 2016, p. 625). Portanto, o Estado democrático contemporâneo atuaria como mediador dos conflitos sociais, entre os quais os conflitos entre as classes sociais, por meio de políticas públicas, mas o faria por mecanismos de participação, tais como as

\footnotetext{
${ }^{8}$ O Brasil, quando do momento em que este texto foi finalizado (meados de junho de 2016), vive situação política marcada pela quebra da ordem constitucional, com a retirada da presidente eleita, Dilma Rousseff, sem base jurídica; com partidos de oposição derrotados nas eleições ocupando o poder; com claros retrocessos sociais devido à reordenação e composição ministerial, assim como, sobretudo, pela desconstrução de políticas públicas que se desenvolviam desde a Constituição de 1988. Trata-se, sem meias-palavras, de golpe de Estado parlamentar, com clara participação de setores do Poder Judiciário e extensa atuação da grande mídia e das classes médias superiores, tais como, nesse caso, analisadas pelo estudo sobre o Programa Mais Médicos. Esse quadro tem isolado o país internacionalmente e levado a instabilidades políticas, sociais e econômicas gravíssimas.
} 
conferências temáticas, caso da conferência de Cidades. Essa forma de gestão "social" dos problemas conferiria maior legitimidade à regulação dos conflitos por meio de um amplo e complexo processo de negociação de interesses, expectativas e percepções ${ }^{9}$.

Os conselheiros de políticas públicas seriam, dessa forma, uma das expressões mais importantes da democracia pós-1988, uma vez que combinariam democracia representativa com democracia direta, assim como democracia institucional (macrossistema de representação) com democracia popular (bottom-up). Os conselhos, as conferências, as audiências públicas e tantas outras formas, inclusive digitais, de participação institucionalizariam a resolução negociada dos conflitos, diminuindo tensões e contradições. Embora inúmeras pesquisas tenham demonstrado a existência de processo de cooptação, sobretudo dos conselheiros pelo poder público e/ou por grupos privilegiados, ainda assim a experiência da participação direta e da representação em nível micro (orçamento participativo, por exemplo) é intrinsecamente relevante ao apontar saída para o impasse da "democracia macroinstitucional", uma vez que distante do cidadão comum.

As disputas, os vetos e os conflitos, que por vezes se manifestam via alianças, coalizões e percepções afins, estão igualmente presentes nos conselhos, nas conferências e nas audiências públicas, tendo em cada um desses lócus um espaço de negociação política em nível local.

Todas as políticas públicas, de dimensões, amplitudes e complexidades distintas - das menores às maiores - passam pelos mesmos processos, embora com particularidades, atores, arenas e dinâmicas distintas.

No texto "Os cuidados paliativos como política pública: notas introdutórias", de Andrea Frossard, analisa-se a importância desses cuidados no contexto de políticas públicas de saúde/qualidade de vida em pacientes terminais. Embora, segundo a autora, o tema possa parecer tópico, na verdade está inserido na lógica da afirmação de uma sociedade de direitos. Afinal: "[...] compreende-se que as políticas sociais decorrem de uma correlação de forças (econômicas, políticas e sociais) presentes em um determinado momento histórico" (FROSSARD, 2016, p. 642).

Toda discussão do texto referenda o papel das políticas públicas inclusivas, argumentando que sua própria existência expressa o conflito de classes sociais, no sentido de ter colocado na agenda governamental prioridades específicas, que se manifestam concretamente, como aludido, por meio de leis, orçamento, recursos humanos, logísticos, entre outros. Portanto, expressariam essencialmente o conflito de classes e grupos sociais, mesmo em programas tópicos.

Por fim, a "cultura" como espaço de disputa e como política pública é analisada no texto "O campo das políticas culturais em Rio Grande-RS diante das mudanças propostas no Governo Lula", de Larisse Kupski e Rosimeri C. Silva. Trata-se de estudo de caso, inspirado na abordagem de Pierre Bourdieu, e capaz de ser "universalizado" no sentido dos conflitos nele existentes serem observados em situações similares. Para as autoras:

Pode-se perceber que houve uma expansão nas políticas públicas federais que passaram a gerar novas ações voltadas à cultura por todo o país. Embora essas políticas sejam definidas e formalizadas em nível federal, de forma a induzir mudanças no país como um todo, elas são fruto de reivindicações e lutas espalhadas por todo o país e é no nível local, logo, nos municípios, que são desenvolvidas (KUPSKI e SILVA, 2016, p. 660).

Essa passagem ilustra que o campo cultural está igualmente eivado de projetos, percepções e interesses diversos quanto à formulação de políticas públicas. Conflitos distintos, como os referentes à cultura "erudita" versus a cultura "popular", e o que se considera e se legitima como cultura, por exemplo, implicaram lutas políticas que, durante o Governo Lula, obtiveram protagonismo. Daí sua expansão da União aos municípios, criando, nestes, estímulos para a elaboração, com participação popular, de Planos Municipais de Cultura, em que interesses de grupos culturais e mercantis, entre outros, conflitam por recursos e políticas públicas que os viabilize. Afinal, segundo as autoras, até a existência das políticas federais de estímulo a políticas públicas locais de cunho plural e popular, no município de Rio Grande/RS: "[...] as políticas para a cultura sempre

\footnotetext{
${ }^{9}$ Ainda segundo Claus Offe, a legitimidade democrática, cujos objetivos seriam, como vimos, reproduzir a lógica da "reprodução da sociedade de classes" por meio da concretização da "forma mercadoria" (capital e trabalho) implica manter a dominação, mas de forma a garantir legitimidade. Para o autor: "[...] em outras palavras: o Estado capitalista está sujeito a uma dupla determinação do poder político - segundo sua forma institucional, este poder é determinado pelas regras do governo democrático-representativo; segundo o seu conteúdo, é determinado pelo desenvolvimento e pelos requisitos do processo de acumulação" (OFFE, 1984, p. 124-125, grifo do autor). No artigo sobre as "Dimensões críticas das políticas públicas" (FONSECA, 2013) reproduzi essas mesmas passagens. O objetivo, tanto naquele como neste artigo, é chamar a atenção para dimensões estruturais que delimitam o poder do Estado perante o capital no que tange à efetivação de políticas públicas.
} 
estiveram associadas a uma visão elitista e com uma ação restrita, voltada para a prática de eventos ou espetáculos, aliada a um entendimento da cultura como patrimônio material”' (KUPSKI e SILVA, 2016, p. 663).

Portanto, a cultura como "expressão do poder dominante" teria sido interrompida por meio de políticas públicas induzidas pelo Governo Federal, em que normatizações, institucionalidades e recursos passaram a permitir a manifestação da pluralidade societal e cultural dos habitantes dos municípios. Trata-se do papel transformador da ação política - encarnada em políticas públicas - perante certas realidades, quebrando ciclos históricos e geracionais de dominação ${ }^{10}$. Embora nem sempre isso ocorra com as políticas públicas, há potencialidades em sua ação, tendo em vista contrariar interesses e tonar mais equânime uma dada sociedade, caso do estudo em tela.

Os conflitos representam, dessa forma, a trama das políticas públicas.

\section{CONSIDERAÇÕES FINAIS}

Este artigo intentou ir além da apresentação formal dos artigos incluídos no número especial deste Cadernos EBAPE.BR, sobre “As Múltiplas Dimensões das Políticas Públicas", ao procurar demonstrar, de fato, como tais dimensões, notadamente referentes ao conflito, operam.

Daí refletir sobre os artigos mais conceituais no início do texto, com vistas a demonstrar o caráter mais aplicado das políticas públicas nos artigos mais empíricos ou voltados a políticas específicas (os referidos "projetos em disputa") na segunda parte do texto.

Não se almejou fazer inventário das teorias sobre políticas públicas - embora várias delas apareçam nos artigos que compõem este número especial, inclusive nos estudos mais aplicados -, mas, sim, articular este conjunto de artigos selecionados de tal forma que sustentasse uma ideia central: a necessidade de se refletir sobre políticas públicas de forma crítica e profunda, cuja ideia de trama implica contradição e complexidade. Para tanto, deve-se resgatar categorias conceituais que têm sido negligenciadas: conflito, disputas, vetos e tudo aquilo que estruturalmente está por trás das políticas públicas, isto é, o modelo de acumulação capitalista, as classes sociais, os grupos de interesse, as relações e percepções de ganhos e perdas, as estratégicas e táticas adotadas pelos atores, entre outras.

Mesmo que, por vezes, os artigos não façam referência explícita a tais categorias, está clara sua presença, tendo em vista o papel assumido pelos atores e a substância das políticas em disputa.

Cabe ressaltar que o campo das políticas públicas é complexo, contraditório, extenso e profundo, o que implica analisá-lo de forma crítica, tendo a Ciência Política e suas fronteiras (caso da sociologia política, da economia política, da filosofia política e da administração política, entre outras) como balizadoras teórico/metodológicas da reflexão.

Este artigo almejou, portanto, chamar atenção para a necessidade de estudos que reforcem a análise - conceitual e empírica - sobre as dimensões do conflito: tipos, formas, dinâmicas, objetivos, alianças, elementos simbólicos, percepções, apoios e vetor, formas de viabilização, contornos, atores, entre inúmeras outras variáveis inseridas na lógica da 'trama': como emaranhado complexo e como articulação de poder com vistas a propor e/ou vetor políticas. Contrariamente, procurou-se criticar perspectivas normativas, formalistas e teóricas/metafísicas, seja por não compreenderem a realidade, seja por edulcorá-la.

Para tanto, o quadro político de desconstrução do Estado de bem-estar social que está ocorrendo em diversos lugares, caso da Argentina e caso do atual processo de impeachment da presidente Dilma Rousseff no Brasil - sem que houvesse qualquer crime de responsabilidade comprovado até o momento em que este texto foi escrito -, expressa com clareza cristalina os móveis das disputas políticas travestidas nas políticas públicas.

Por fim, este número especial do Cadernos EBAPE.BR espera que outros estudos se apropriem de categorias esquecidas e de outras que poderão vir à tona na 'trama conflituosa das políticas públicas', cujas lógicas e projetos em disputa são marcados por vetos, coalizões e arranjos diversos.

\footnotetext{
$\overline{10}$ Robert Dahl (1972), em seu livro clássico sobre as possibilidades da democracia, isto é, a "poliarquia" como tipo ideal ou aproximação de elementos basilares - tais como a possibilidade de participação, contestação e influência nas decisões governamentais, entre outras -, entende que a ação política pode ser transformadora, para além das estruturas históricas. Há, portanto, para os fins deste texto, clara tensão entre, de um lado, condicionantes estruturais, tais como os analisados por Offe e por diversos trabalhos aplicados comentados neste artigo e, de outro lado, ênfase na ação política como transformadora, caso da obra de Dahl e de outros artigos aqui mencionados.
} 


\section{REFERÊNCIAS}

ANDRADE, J. A. de; CORDEIRO NETO, J. R. Uma Discussão sobre a Possibilidade da Criação Institucional e Sinergia entre Estado e Sociedade: o Caso do PIMC no Seminário Brasileiro. Cad. EBAPE.BR, v. 14, n. Edição Especial, p. 551-568, 2016.

BAUMGARTNER, F. R; JONES, B. D. Agendas and Instability in American Politics. Chicago: University of Chicago Press, 1993.

BORGES, M. S.; GUEDES, C. A. M.; CASTRO, M. C. D. Programa de Assistência Técnica para o Desenvolvimento de Pequenas Propriedades em Valença-RJ e Região Sul Fluminense. Cad. EBAPE.BR, v. 14, n. Edição Especial, p. 569- 592, 2016.

BOURDIEU, P. O Campo Científico. Disponível em: <http://www. cetkinformatica.com.br/DOWNLOADS/O-Campo-Cient\%C3\%ADficoPierre-Bourdieu.pdf>. Acessado em 27 de junho de 2016.

CAPELLA, A. C. N. Um Estudo sobre o Conceito de Empreendedor de Políticas Públicas: Ideais, Interesses e Mudanças. Cad. EBAPE.BR, v. 14, n. Edição Especial, p. 486-505, 2016.

COELHO, D. B.; OLIVEIRA JR., M. de M. A Internacionalização de Empresas na Agenda Governamental Contemporânea de Desenvolvimento: Reflexões Críticas e Analíticas para os Negócios Internacionais. Cad. EBAPE.BR, v. 14, n. Edição Especial, p. 527-550, 2016.

CUNHA, B. Q. Antagonismo, Modernismo e Inércia: A Política Regulatória Brasileira em Três Atos. Cad. EBAPE.BR, v. 14, n. Edição Especial, p. 473-485, 2016.

DAHL, R. Polyarchy: participation and opposition. New Haven, CT: Yale University Press, 1972.

EBELING, F. Variedades de Capitalismo e Complementaridades Institucionais: Uma Análise da Política Petrolífera Brasileira e da Viabilidade do 'Projeto Pré-Sal'. Cad. EBAPE.BR, v. 14, n. Edição Especial, p. 418-439, 2016.

FONSECA, F. O consenso forjado: a grande imprensa e a formação da agenda ultraliberal no Brasil. São Paulo: Hucitec, 2005.
FONSECA, F. Mídia e poder: elementos conceituais e empíricos para o desenvolvimento da democracia brasileira. Brasília (DF): Ipea, 2010. (Texto para Discussão n. 1.509).

FONSECA, F. Dimensões críticas das políticas públicas. Cad. EBAPE. BR, v. 11, n. 3, p. 402-418, 2013.

FROSSARD, A. G. "Os Cuidados Paliativos como Política Pública: Notas Introdutórias. Cad. EBAPE.BR, v. 14, n. Edição Especial, p. 640-655, 2016.

KUPSKI, L.; SILVA, R. C. da. O Campo das Políticas Públicas Culturais em Rio Grande-RS diante das Mudanças Propostas no Governo Lula. Cad. EBAPE.BR, v. 14, n. Edição Especial, p. 656-671, 2016.

LESSA, C. O Estado de bem-estar social na idade da razão. Rio de Janeiro: Campus, 2012.

MACEDO, A. dos S. et al. O Papel dos Atores na Formulação e Implementação de Políticas Públicas: Dinâmicas, Conflitos e Interesses no Programa Mais Médias. Cad. EBAPE.BR, v. 14, n. Edição Especial, p. 593-618, 2016.

MATUS, C. O plano como aposta. 1991. Disponível em: <http://www. cgca.com.br/userfiles/file/O\%20Plano\%20Como\%20Aposta\%20 por\%20Carlos\%20Matus.pdf>. Acesso em: 17 jun. 2016.

OFFE, C. Problemas estruturais do Estado capitalista. Rio de Janeiro: Tempo Brasileiro, 1984.

ROCHA, J. M.; BORGES, D. F. Políticas públicas coordenadas e presidencialismo de coalizão: o caso do Promeso. Cad. EBAPE.BR, v. 14, n. Edição Especial, p. 440-472, 2016.

SILVEIRA, A. D. et al. Análise do Sistema Nacional de Inovação no setor de energia na perspectiva das políticas públicas brasileiras. Cad. EBAPE.BR, v. 14, n. Edição Especial, p. 506-526, 2016.

VILLELA, L. E. et al. A Conferência Nacional de Cidades como Instrumento de Políticas Públicas para o Desenvolvimento Territorial: a Percepção dos Conselheiros nos Processos Participativos e Deliberativos. Cad. EBAPE.BR, v. 14, n. Edição Especial, p. 619-639, 2016.

Francisco Fonseca

Bacharel em ciências sociais (PUC/SP), mestre em ciência política (Unicamp) e doutor em História Social (USP); É professor de ciência política nos cursos de graduação e pós-graduação em Administração Pública na Escola de Administração de Empresas de São Paulo (Eaesp) da Fundação Getulio Vargas (FGV), Departamento de Gestão Pública (GEP); e professor de ciência política na Pontifícia Universidade Católica de São Paulo (PUC/SP), Departamento de Política; Membro da linha de pesquisa "Governo e Sociedade Civil em Contexto Subnacional” do Programa de Pós-Graduação em Administração Pública e Governo (Eaesp/FGV) e do Centro de Estudos em Administração Pública e Governo (Ceapg- Eaesp/FGV). E-mail: francisco.fonseca@fgv.br 